\title{
SMART AUTOMOBILE SECURITY SYSTEM USING LABVIEW
}

\author{
N. Chandra Kumar ${ }^{1}$, M. Dinesh Kumar ${ }^{2}$, D.Gokul ${ }^{3}$ S.Sakthivel ${ }^{4}$ \\ ${ }^{1}$ Bachelor of Electronics and Communication Engineering, Knowledge Institute of Technology \\ ${ }^{2}$ Assistant Professor, Electronics and Communication Engineering, Knowledge Institute of Technology, India \\ ${ }^{3}$ Bachelor of Electronics and Communication Engineering, Knowledge Institute of Technology \\ ${ }^{4}$ Bachelor of Electronics and Communication Engineering, Knowledge Institute of Technology
}

\begin{abstract}
Automobile industry has undergone a rapid development in last two decades. It's becoming the progressive symbol of the modern society. Today automobile security is one of the challenging issues in our society. All these security systems are using many sensors, so the cost of implementation is high. This project will deal with the design and development of an embedded system, which will be used to prevent/control the theft of a vehicle. The development model will be based on embedded system with GSM technology. The main theme of this project is to control the outlet of the fuel injector by means of electronic solenoid valve, which will be controlled by the microcontroller through the driver circuit. The driver circuit will drive the solenoid valve. Thus the enabling and disabling of solenoid valve will be controlled by the microcontroller. The password is given to the authorized person of the vehicle (owner and driver) to start it by enter the keyword. If he enters the keyword, the normally closed solenoid opens and the vehicles will be ready to start. If the password is entered by the unauthorized person, the system will send an alert message to the authorized person through GSM to safeguard their vehicle. An alarm attached to the system will give a warning sound. The LCD is be used to display the systems functionality. This project can be simulated using the LABVIEW platform.
\end{abstract}

Keywords: GSM technology, Labview, Electronic Fuel Injector

$* * *$

\section{INTRODUCTION}

The security system has been enhanced in all fields in the society. Automobile security has also attained many rapid changes, but the costs of all the security upgrades are so high and it is not affordable for all the vehicle owners ${ }^{[3] .}$

This project is aimed to give the best security solution for the automobiles at affordable cost. In this we have incorporated the GSM technology and the labview platform to design a more secure and user-friendly automobile security system. The concept of igniting the engine with the air is generally used, the spark in the engine, that is used to ignite an engine canbe prevented by blocking the flow of air to the engine ${ }^{[5][6]}$.

The GSM is being used in our project as it has a better coverage in both indoor and outdoor environment. And the GSM being a leading $2 \mathrm{G}$ technology is available in all countries throughout the world and the cost of the communication is also low ${ }^{[3]}$.

The cost of implementing this smart security system with labview software is a cost effective and highly safe system[9]. The user interface for the system is all so simple and can easily be understood by all people. The main process of this system takes place in the fuel injector of the automobile and so there will not be any extra hardware for the system. The GSM system will be inside an undisclosed frame of the automobile [3][5][9].

\section{LITERATURE REVIEW}

Zhen-hue Wang, Xue-ping Zhang, Ge-fei Yu, Yuan-fu Lin, Lei Chen

They proposed the populations of cars bring the convenience and happiness of living, but people are becoming more and more worried about the frequent loss of the cars. In this paper, an automobile security system is designed by adopting AT89C2051 and A7102C wireless transceiver. This system can use specific signal detecting means and support different alarming measure, which helps patrolmen and security guards quickly and correctly find the first crime evidence. Goel and V. Gruhn

They proposed a vehicle tracking system is an electronic device installed in a vehicle to enable the owner or a third party to track the vehicle's location. This paper proposed to design a vehicle tracking system that works using GPS and GSM technology, which would be the cheapest source of vehicle tracking and it would work as anti-theft system. It is an embedded system which is used for tracking and positioning of any vehicle by using Global Positioning System (GPS) and Global system for mobile communication (GSM). This design will continuously monitor a moving Vehicle and report the status of the Vehicle on demand. For doing so an AT89C51 microcontroller is interfaced serially to a GSM Modem and GPS Receiver. A GSM modem is used to send the position (Latitude and Longitude) of the vehicle from a remote place. The GPS modem will 
continuously give the data i.e. the latitude and longitude indicating the position of the vehicle. The same data is sent to the mobile at the other end from where the position of the vehicle is demanded. When the request is sent to the number at the GSM modem, the system automatically sends a return reply to that mobile.

\section{EXISTING METHODS:}

Now there are three main methods used for providing security to automobiles. They are electronic immobilizer, vehicle tracking system and car alarm. But the costs of manufacturing these systems are quite high when comparing to the proposed system. And we can easily deactivate the warning alarm present in car security system. In developing economies where the market for car is high the people are not able to get access to high cost security systems.

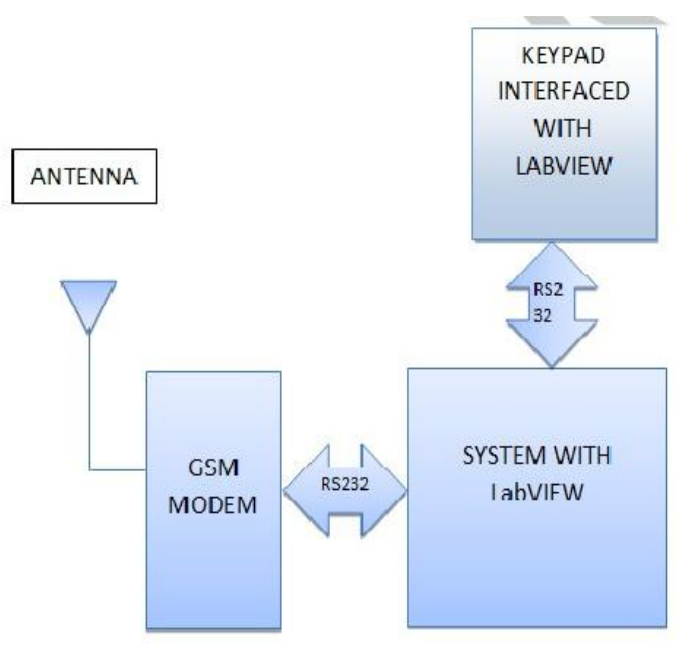

Fig.1 security system block diagram

\section{METHODOLOGY}

To make the system secure a password is given to the authorized person of the vehicle. To start the vehicle he has to enter the correct password. On entering the correct password the solenoid valve in the fuel injector of the vehicle engine air inlet opens and the engine ignites for the vehicle to move ${ }^{[2]}$.

If the wrong password is entered the normally closed solenoid valve remains closed solenoid valve remains closed and an instruction is send to the GSM by the labview and an alert message is send to the authorized person. It also displays in the LCD display as "invalid password". And an alarm rings simultaneously to alert the people around the vehicle about the theft ${ }^{[4][3] \text {. }}$

Now as the solenoid valve remains closed the fuel to the engine is completely shut and so the engine cannot produce spark needed to start the engine.

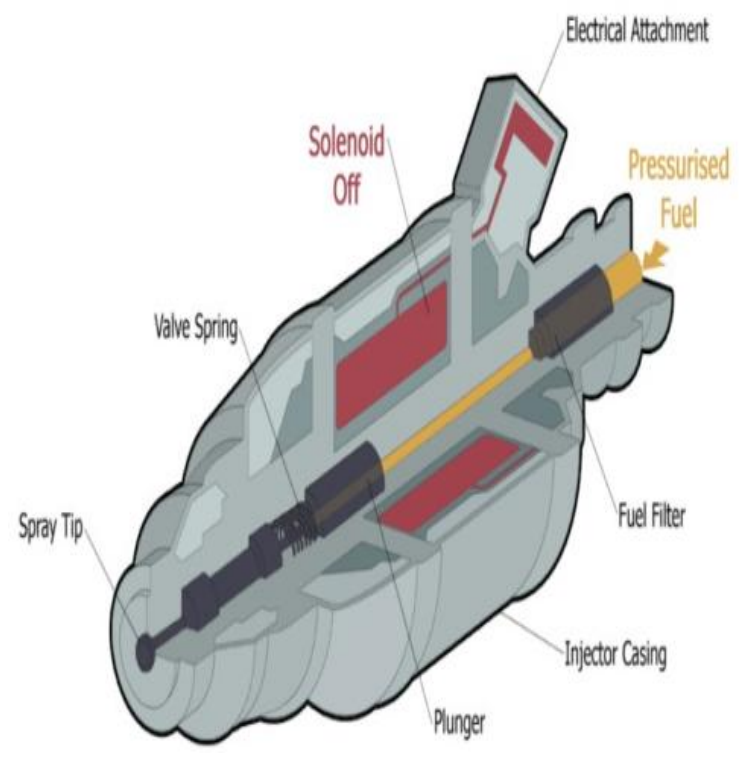

Fig.2 fuel injector

This is used to stop the movement of the vehicle [2][5]. Then the movement of the vehicle is arrested and an simultaneous operation of GSM sends the alert message to the authorized person of the vehicle through their mobile phones or other cellular messaging system using the GSM technology. GSM has wide coverage and message will be sent without any chance for failure.

The following block diagram (Fig.2) will show the hierarchy wise functioning of the electronic solenoid valve in the fuel injector to control the flow of fuel to the vehicles engine [5].

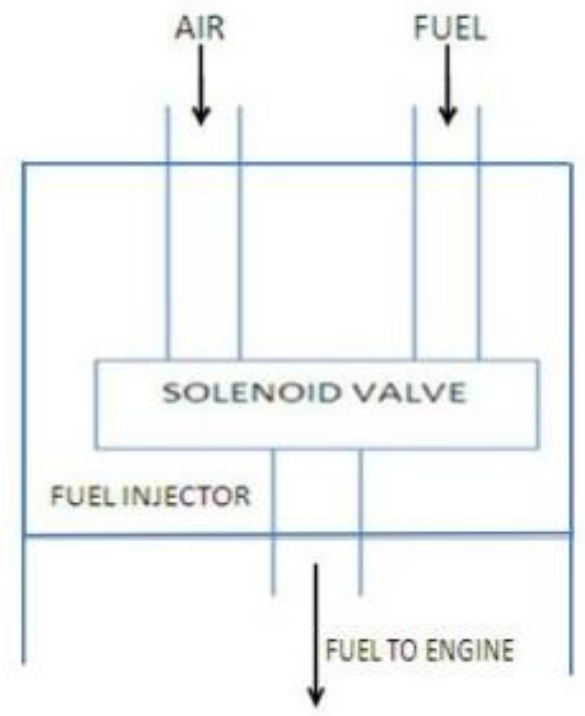

Fig.3 fuel injector with solenoid valve 
The LCD is used in this system to know the status of the security locking system of the vehicle and it act as the interface between user and the security system ${ }^{[7][5]}$.

\subsection{Flow of Operation}

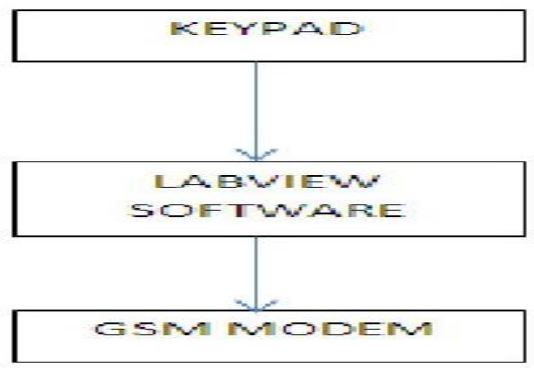

Fig.4 flow of operation

1. The keypad section is the interface between the automobile user and the security system.

2. The labview is the medium or the software that controls all the hardware components of the security system like the fuel injector, GSM modem.

3. GSM modem is used to intimate the users about the theft.

\subsection{Labview}

A key of Labview over other development environments is the extensive support for accessing instrumentation hardware. Drivers and abstraction layers for many different types of instruments and buses are included or are available for inclusion. These present themselves as graphical nodes. The abstraction layers offer standard software interfaces to communicate with hardware devices. The provided driver interfaces save program development time.

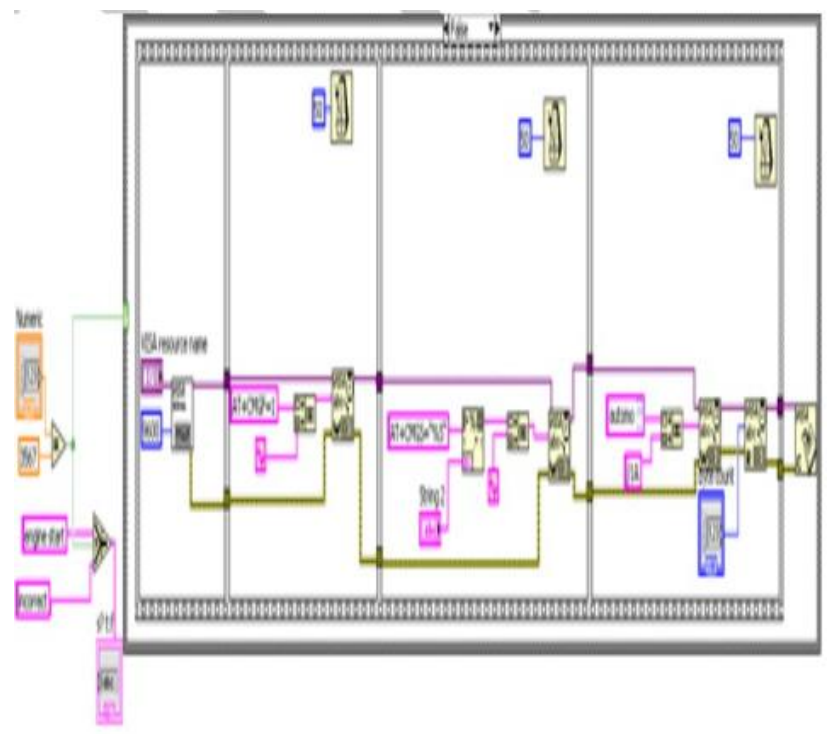

Fig. 5 labview back panel

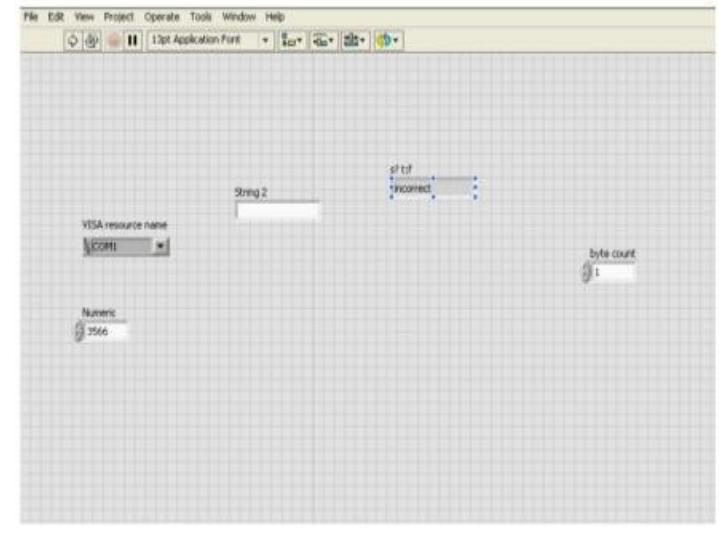

Fig 6 labview fornt panel

\subsection{GSM Security System}

GSM technology has been used in the security system for the process of authentication of the registered subscribers and so it can be used in the security system to alert the vehicle owners. It has wide network coverage and this makes this as a more efficient way to transfer the data. The data transfer through the GSM technology is more secure as it uses encryption technique to send the alert message.

\subsection{Fuel Injector}

Fuel injection is a system for admitting fuel into an internal combustion engine. It has become the primary fuel delivery system used in automotive engines. The engine control unit is to calculate the appropriate amount of fuel to inject. When signaled by the engine control unit the fuel injector opens and sprays the pressurized fuel into the engine. The duration that the injector is open is proportional to the amount of fuel delivered.

\section{CONCLUSIONS}

By implementing our system in real time we can control the theft of vehicles and give a more secure system for the automobile industry at a very affordable cost. This security system is user friendly and can be easily used by any person.

\section{REFERENCES}

[1] Jr., William M. Assistant Examiner: Ganjoo, Peter on Anti-theft system for use with unattended and attended vehicles comprising: a base microprocessor, IEEE.

[2] Zhen-hua Wang, Xue-ping Zhang, Ge-fei Yu, Yuan-fu Lin, Lei Chen, "A New Automobile Anti-interference Alarm System Based on Signal Detecting Technique to Design and Implement," iccsee, vol. 1, pp.310-312, 2012 International Conference on Computer Science and Electronics Engineering, 2012

[3] Goel and V. Gruhn, "Fleet Monitoring System for Advanced Tracking of Commercial Vehicles", Proceedings of the 2006 IEEE International Conference 
on Systems, Man, and Cybernetics (SMC 2006), pp. 2517-2522, Taipei, Taiwan,08.10.2006-11.10.2006.

[4] Chia-Hung Lien, Chi-Hsiung Lin, Ying-WenBai, Ming-Fong Liu and Ming-Bo Lin, 2006 IEEE Tenth International Symposium on Consumer Electronics (ISCE 2006), St. Petersburg, Russia, pp. 7-12, June 28-July 1, 2006.

[5] E. D. Kalpan, Understanding GPS: Principles and Applications, Artech house Publishers, ISBN 0890067937, February 1996. "Implementation of GSM based Commercial Automobile Tracker Using PIC 18F452"Proceedings of 2009 IEEE student conference on Research and development (SCOReD 2009), 16-18 Nov, 2009, UPM Serdang, Malaysia.

[6] M. McDonald, H. Keller, J. Klijnhout and V. Mauro, "Intelligent Transport Systems in Europe: Opportunity for Future Research"World Scientific Publishing Company, ISBN 981270082X, 2006.Muhammad Ali Mazidi, Janice Gillespie, Mckinlay, Rolin D., " The Microcontroller in Embedded System.

[7] Raj Kamal, "Embedded System- Architecture, Programming and Design", Tata McGraw Hill Publisher, 2nd edition, 2008.

[8] Junaid Ali, ShaibNasim, Taha Ali, Naveed Ahmed and syed Riaz un Nabi, "Implementation of GSM based Commercial Automobile Tracker Using PIC 18F452 and Development of Google Earth Embedded Monitoring Software" Proceedings2009 IEEE student.

[9] Jayanta Kumar Pany1 \& R. N. Das ChoudhuryEmbedded Automobile Engine Locking System, Using GSM TechnologyB.G. Nagaraja, Ravi Rayappa, M. Mahesh, Chandrasekhar M. Patil, Dr. T.C. Manjunath:- "Design \& Development of a GSM Based Vehicle Theft Control System" 978-0-7695-35166/ 08@2008 IEEE, DOI10.1109 /ICACC.2009. 